\title{
Five Approaches to Music as Health Promotion
}

\author{
Lars Ole Bonde* \\ Aalborg University, Denmark \\ *Corresponding author: Lars Ole Bonde, Aalborg University, Denmark
}

\begin{tabular}{|c|c|}
\hline ARTICLE INFO & ABSTRACT \\
\hline Received: 幽 February 21, 2019 & $\begin{array}{l}\text { Citation: Lars Ole Bonde. Five Approaches to Music as Health Promotion. Biomed J Sci \& } \\
\text { Tech Res 15(3)-2019. BISTR. MS.ID.002696. }\end{array}$ \\
\hline Published: 幽 March 01, 2019 & \\
\hline
\end{tabular}

\section{Introduction}

The Danish" think tank" Music \& Health has since 2018 based its work on this overview, where approaches to music as health promotion is divided into five different areas or fields with each their agents. - The overview was developed by professor emeritus in music therapy, Lars Ole Bonde, Aalborg University (DK).

\section{Health Promoting Music Initiatives can be Designed within this Classification}

\subsection{Music Therapy}

Music therapy is the specialized expertise in the use of music as a treatment modality for both mental and somatic disorders. The music therapy environment at Aalborg University accounts for most of the existing Danish research within the field and is a leading international agent. Music therapy is practiced in the treatment system by university-trained music therapists (candidates in music therapy), and the following tasks are typical:

a) treating patients with special needs one-on-one;

b) offering tailor-made interventions to larger or smaller groups,

c) developing environmental therapeutic services,

d) advising and educating staff in using music interventions and music medicine at the institution or hospital's daily practice.

Examples: Case from psychiatry - in Jacobsen, Pedersen \& Bonde (2019), pp. 246-254. Many other cases in the same book.

Literature: Jacobsen, S.L., Pedersen, I.N., \& Bonde, L.O. (eds.) (2019). Music Therapy. Theory - Education - Practice - Research. London: Jessica Kingsley Publishers.
Aalborg University hosts a virtual research center, CEDOMUS: https://www.musikterapi.aau.dk/cedomus/ - with extensive introductions to music therapy in theory, practice and research articles, links, videos etc.

\subsection{Music Medicine}

Music Medicine is the use of music (played live or through various, often specially designed playback equipment) for the benefit of hospital patients, outpatients or citizens in special institutions, in treatment as well as in the rehabilitation phase and in palliative care. Many different players are active here: Some composers provide specially composed music for different purposes, e.g. music for ambulances. Professional musicians play for patients with a stated treatment goal, such as reducing anxiety or depression. Music medicine must be prescribed in close dialogue with doctors, nurses and trained music therapists.

a) Examples: "The Music Star", an app developed by music therapists at Aalborg UH Psychiatry. - Live music medicine is the subject of Margrethe Langer Bro's PhD thesis (2019)

b) Literature: Jacobsen, Pedersen \& Bonde (2019), chapter 3.9 Lund H, Bertelsen L, Bonde L O (2016) Sound and music interventions in psychiatry at Aalborg University Hospital. Sound Effects - An Interdisciplinary Journal of Sound and Sound Experience 6 (1): 48-68. https://doi.org/10.7146/ se.v6i1.24912

\subsection{Health Musicians}

"Health musicians" are most often professional musicians who use their skills and commitment to create joy, engagement and improved quality of life for patients in hospitals and care centres 
through specially organized and personalized live performances. This is neither music therapy nor music medicine, as it does not have an intended treatment component, however, it can be having a therapeutic effect anyway, if the patient is ready and open for the experience. To a certain extent, the area is self-regulating and currently in growth - parallel to hospital clowns, who are also a non-treatment-oriented offer, $100 \%$ based on private funding.

a) Example: "MusikBeRiget"/" The Music Mission" - Lisbeth Sagen's long-standing project for (cancer) patients at the Copenhagen University Hospital.

b) Literature: Ruud E (2012) The New Health Musicians. In: MacDonald, R Kreutz G, Mitchell L, (Eds.), (2012). Music, health, \& Wellbeing, pp.87-96. Oxford: Oxford University Press.

\subsection{Music as Health Promotion}

Specially designed music experiences are included - in line with other cultural experiences - in a number of "Culture on Prescription" projects, locally in the municipality of Aalborg - inspired by Swedish projects in the region of Skåne. Here we talk about authentic art experiences that are used to promote health - not as treatment offered by therapists but based on the well-documented knowledge that art experiences can have a health-promoting function. In Aalborg, the Northern Jutland Center of Culture and Health (NOCKS) is an interdisciplinary and cross-sectoral research and

\section{ISSN: 2574-1241}

DOI: 10.26717/BJSTR.2019.15.002696

Lars Ole Bonde. Biomed J Sci \& Tech Res

This work is licensed under Creative Commons Attribution 4.0 License

Submission Link: https://biomedres.us/submit-manuscript.php development center that develops initiatives within this subfield.

a) Example: "Cultural Vitamins", a project for long-term sick people in the municipality of Aalborg. A report is available online.

b) Literature: Jacobsen, Pedersen \& Bonde (2019), chapter 3.11.

\subsection{Music as Diversion / Entertainment}

Music as a diversion / entertainment in hospitals and institutions. More technological solutions are currently being developed, such as apps specifically aimed at hospital patients or people with dementia. The area is interesting in the context if specially composed music is included, and / or if the music selection is based on professional expertise on e.g. music for the regulation of arousal.

a) Example: The "Music Mind" App. with playlists developed specifically for care centres (with elements of music medicine, as one of the purposes is regulation of arousal)

b) Literature: https://musicmind.me/\#!/s

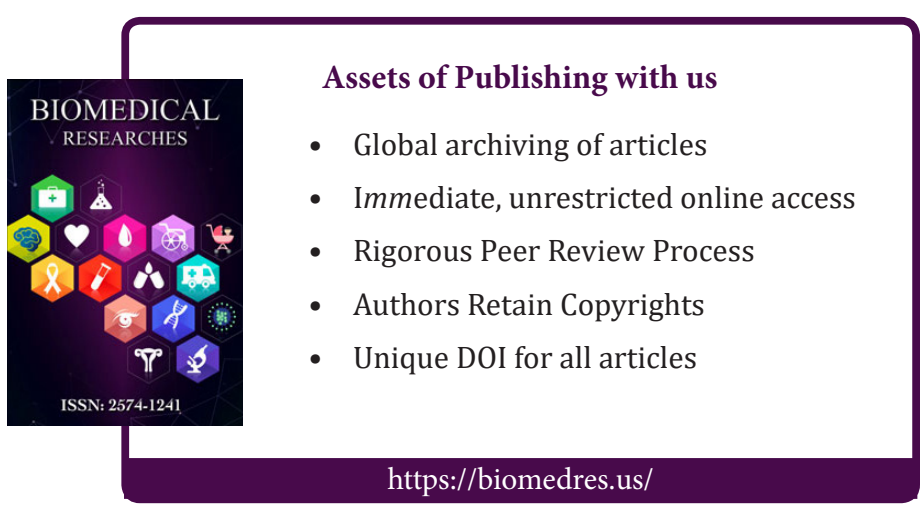

